\title{
Effect of Filler Metal on the Performance of 2205 Duplex Stainless Steel Weldments.
}

\author{
M.A.Khadrawy ${ }^{1}$, A. AbdelFatah ${ }^{2}$, M Ahmadein ${ }^{1.3}$, Hanafy M Hendawy ${ }^{1}$ Ezzat A.Showaib ${ }^{1}$ \\ Production Engineering and Mechanical Design Department, Tanta University, Tanta, Egypt. \\ ${ }^{2}$ Metallurgy Department, Faculty of Engineering, Cairo University. \\ ${ }^{3}$ Department of Mechanical Engineering, Imam Mohammad Ibn Saud Islamic University, Saudi Arabia
}

\begin{abstract}
The escalated concern in duplex stainless steels by industries is due to their best mechanical and corrosion resistance properties. In this paper, the mechanical properties of welded joints made of duplex stainless steel 2205 were investigated. The joints were made by the GTAW process using different filler wires: duplex ER2209 and austenitic ER312. The microstructure realized by the duplex filler ER2209 is similar to that of the base material duplex 2205 , but when connected with the austenite filler ER312, the phase ratio of ferrite $(\delta)$ to austenite $(\gamma)$ is increased. The influence of the fillers on the weld metal mechanical properties such as impact resistance, ultimate tensile properties and the hardness measurement was evaluated. The microstructure phases produced for the different fillers causes variation of mechanical properties. Increasing the ferrite number using ER 312 filler wire resulted in a decrease in the absorbed energies of the impact test of the weld metal. On the other hand, tensile strength values were enhanced by increasing the ferrite percent.
\end{abstract}

Keywords: duplex stainless steel; gas tungsten arc welding; pitting properties; Filler metal; Microstructure and mechanical properties.

\section{INTRODUCTION}

The growing interest in duplex stainless steels by industries is due to their best mechanical and corrosion resistance properties, that show over other stainless and structural steels. Thanks to the high percentage of molybdenum in their composition, duplex stainless steels show excellent resistance to localized pitting corrosion, which gives them a PREN between 30 and 50[1].

However, this value may be modified during the welding processes, particularly in those that include filler material, due to the possible modification of the proportions of the alloying elements. This requires careful selection of the filler material during welding operations [2].

The right selection of welding parameters such as preheat, inter-pass temperature, shielding gas, heat input, and the most appropriate choice of proper filler metal, will enable to obtain a desirable microstructure and mechanical characteristics of weldment.

The use of the duplex stainless is frequently limited to an upper and lower service temperature generally between -40 and $250{ }^{\circ} \mathrm{C}$, where it has good mechanical properties better than ferritic and austenitic steel [3].

At sub-zero temperatures the duplex stainless steels exhibit a ductile to brittle transition, where the ferrite becomes increasingly brittle [4]. The temperature for the ductile to brittle transition depends on the chemical composition and the ferrite phase content $[5,6]$. The ferrite content increased as the Creq / Nieq ratio increased [7]. The addition of nickel and nitrogen in the metal deposited leads to increase the impact toughness particularly at low temperature $[8,9]$. It has also been lighted that the effect of the alloying elements on the ferrite/ austenite ratio is much more important than the cooling rate [10].

\section{EXPERIMENTAL PROCEDURE}

2205 grade duplex stainless steel in the form of plates of 8 mm thickness was considered. A multi-pass welding was performed using GTA welding process with ER2209 and ER312 filler metals. The chemical composition of the base metal and filler metals is given in Table 1. The two welds are performed by the same qualified welder, who executes each pass carefully and following a welding procedure specification (WPS), established from qualification tests, containing well-defined welding parameters. The welding energy $E(\mathrm{~kJ} / \mathrm{mm})$ depends on the welding current (I), welding voltage $(\mathrm{V})$, and welding speed $\mathrm{S}(\mathrm{mm} / \mathrm{min})$ by the following relation [11]:

$$
\mathrm{E}=60 * \mathrm{I} * \mathrm{~V} / \mathrm{S} * 1000
$$

Table 1. Chemical analysis of base metal and filler metals (WT.\%)

\begin{tabular}{|c|c|c|c|}
\hline Element & 2205 & ER 2209 & ER 312 \\
\hline $\mathbf{C}$ & 0.015 & 0.02 & 0.10 \\
$\mathbf{M n}$ & 1.27 & 1.57 & 1.6 \\
$\mathbf{S i}$ & .42 & 0.46 & 0.4 \\
$\mathbf{S}$ & .0005 & 0.010 & 0.03 \\
$\mathbf{P}$ & .026 & 0.01 & 0.03 \\
$\mathbf{C r}$ & 22.15 & 22.9 & 30.7 \\
$\mathbf{N i}$ & 6.22 & 8.6 & 8.8 \\
$\mathbf{M o}$ & 3.19 & 3.1 & 0.2 \\
$\mathbf{C u}$ & 0.28 & 0.1 & 0.14 \\
$\mathbf{N b}$ & - & 0.01 & - \\
$\mathbf{N}$ & - & - & 0.25 \\
Creq/Nieq & 0.967 & 2.03 & 2.5 \\
PREN & 32.36 & 33.56 & 38.86 \\
\hline
\end{tabular}

A radiographic test (RT) was performed on the welds, and it shows that the two joints are accepted. Duplex stainless steel 2205 of $8 \mathrm{~mm}$ thickness were used. Joints were butt welded using GTAW and a duplex filler (ER 2209) and austenitic filler ER 312 were used as filler materials.

For the study of the microstructure of the duplex stainless steel and the welds, the surface of cross sections was prepared by grinding and polishing. In order to reveal the microstructure, the polished surface was electrolytic etched using $10 \% \mathrm{KOH}$ solution at $3 \mathrm{~V}$ [12]. 
The percentage by volume of ferrite in the BM, of the heat affected zone (HAZ) and of the weld metal were determined through magnetic measurements using a firritescope.

For the mechanical behavior, specimens are machined from the two welds. Charpy V-notch reduced specimens are prepared with dimensions of $5 \times 10 \times 55 \mathrm{~mm}$ in accordance with ASTM A370 standard. Impact tests were carried out at $\left(-20^{\circ} \mathrm{C}\right)$ for three locations that are (MB, WM, and HAZ) by means of a machine Charpy pendulum with $150 \mathrm{~J}$ impact load [13]. The tensile test is carried out on specimens that are machined in accordance with ASTME8-04 standard [14].

For investigation of the effect of the filler metals on the hardness profile (HV), the measures are taken across the weld metal, HAZ and base metal.

\section{RESULTS AND DISCUSSION}

\subsection{Elemental analyses}

Chemical analysis results of the base metal and the weld metals at the middle points of weld metals obtained using ER 2209 and ER 312 filler metals are given in Table 2. Elemental variations of $\mathrm{Fe}, \mathrm{Ni}, \mathrm{Cr}, \mathrm{Mo}$, which play an important role in microstructure of weld metal. Elemental migration due to dilution was not significant for elements in ER 2209, with regard to ER 312 the $\mathbf{C r}$ has decreased from $30 \%$ to $26.98 \%$ and the Mo has increased from $0.2 \%$ to $0.77 \%$.

\subsection{Ferrite Percent determination}

Figure 1 and Table 3 depict the ferrite number distribution along weld metal, HAZ and base metal. The ferrite numbers for HAZ which is measured by firritescope for 2205 welments using ER 2209, ER 312, were 51.70 \pm 3.5 and 59.06 \pm 2.7 respectively. On the other hand, the experimental ferrite numbers for weld metal were $43.12 \pm 3$ and $65.04 \pm 2.11$, respectively. It is observed that the joint performed using the duplex ER 2209 has no significant change in the ferrite $(\delta)$ to austenite $(\gamma)$ phase ratio. The same that of the base metal and there is no considerable increase in ferrite due to the slight increase in nickel content of the electrode relative to the base metal. While using ER 312, the amount of ferrite was higher for weld metal and HAZ than that obtained using ER 2209 filler.

Table 2. Chemical analysis of base metal and filler metals (WT.\%)

\begin{tabular}{|cccc|}
\hline Element & $\mathbf{2 2 0 5}$ & ER 2209 & ER 312 \\
\hline $\mathbf{S i}$ & 0.421 & 0.731 & - \\
\hline $\mathbf{C r}$ & 21.829 & 22.78 & 26.98 \\
\hline $\mathbf{M n}$ & 1.27 & 1.63 & 1.67 \\
\hline $\mathbf{F e}$ & 65.839 & 63.03 & 59.49 \\
\hline $\mathbf{N i}$ & 6.22 & 8.27 & 7.23 \\
\hline $\mathbf{C u}$ & 0.28 & 0.17 & 0.037 \\
\hline $\mathbf{M o}$ & 3.19 & 3.11 & 0.767 \\
\hline Creq/Nieq & 3.36 & 3.3 & 3.52 \\
\hline
\end{tabular}

Table 3 Ferrite content in the welding zone

\begin{tabular}{|cccc|}
\hline Filler & Base metal & HAZ & Weld metal \\
2205- & $51.46 \_ \pm 1.6$ & $51.70 \_ \pm 3.5$ & $43.12 \pm 3$ \\
ER2209 & & & \\
2205- & $51.70 \pm 4.9$ & $59.06 \pm 2.7$ & $65.04 \pm 2.11$ \\
ER312 & & & \\
\hline
\end{tabular}

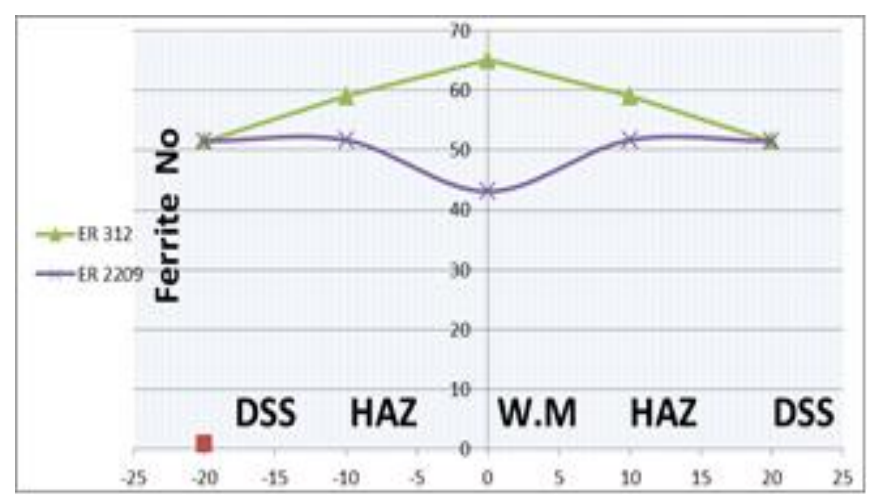

Fig 1: Ferrite distribution

\subsection{Hardness test}

The Vickers hardness measurements for the weld metals, HAZ and 2205 material have been measured in Table 4. According to the hardness profiles presented in Figure 3, ER 2209 was the hardest sample, while the ER 312 weld showed the lowest hardness values despite the high $\mathrm{Cr} \%$ because the ferrite is created in an austenite matrix. In specimen ER 312; the hardness increased from the cap pass to the root pass because the ferrite content increased from the cap to the root. While, in specimen ER 2209 the hardness was decreased from the cap to the root as showed in figure 2 and figure 3 .

Table 4. Vickers hardness for the weld materials

\begin{tabular}{|c|c|c|c|}
\hline \multicolumn{4}{|c|}{ ER 2209} \\
\hline \multicolumn{3}{|c|}{ W.M } & HAZ \\
\hline Cap & Middle & Root & \multirow{2}{*}{245} \\
\hline 245 & 239 & 232 & \\
\hline \multicolumn{4}{|c|}{ ER 312} \\
\hline \multicolumn{3}{|c|}{ W.M } & HAZ \\
\hline Cap & Middle & Root & \multirow[t]{2}{*}{235} \\
\hline 230 & 233 & 264 & \\
\hline \multicolumn{4}{|c|}{ BASE METAL } \\
\hline \multicolumn{4}{|c|}{255} \\
\hline
\end{tabular}

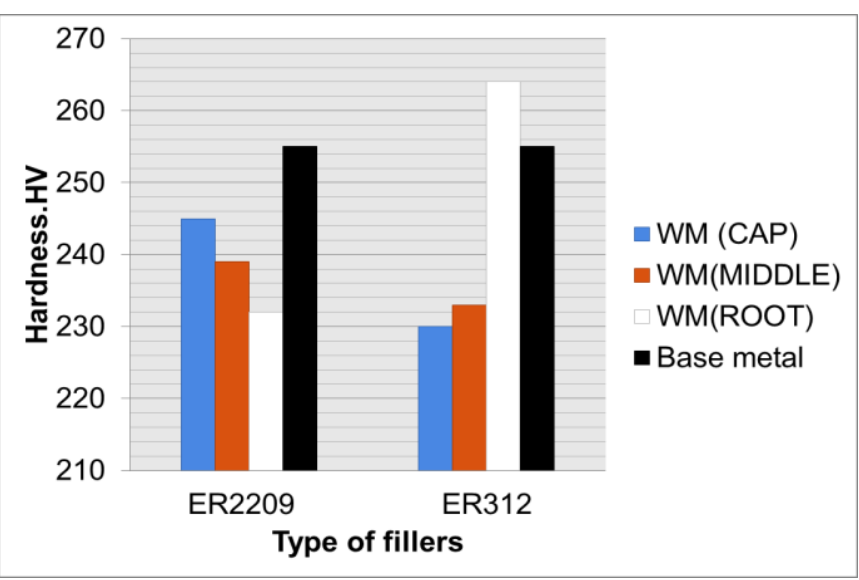

Fig 2: Comparison between hardness of fillers 


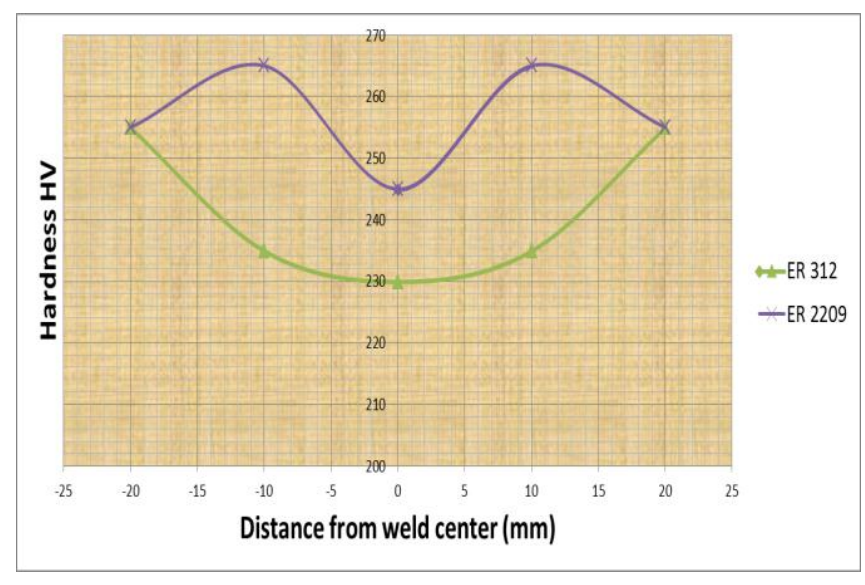

Fig 3: hardness distribution of the fillers

\subsection{Microstructure Examination}

Figure 5 shows the microstructure of HAZ, WM of fillers ER312, ER2209, at the middle of the fusion zone and HAZ, obtained using. In the microstructure, dark-colored areas indicate $\delta$-ferrite, while the light-colored regions indicate the $\gamma$-austenite phase.

The microstructure of the fusion zone welded using ER312 filler exhibited acicular ferrite microstructure in an austenite matrix and grain-boundary austenite, secondary austenite. With regard to ER 22209 exhibited a matrix of ferrite and needles of austenite. The microstructure of austenitic (ER 2209) welds contained grain boundary austenite, the secondary austenite $\left(\gamma_{2}\right)$, and a little widmanstatten austenite.

\section{ER 312 -Weld metal}

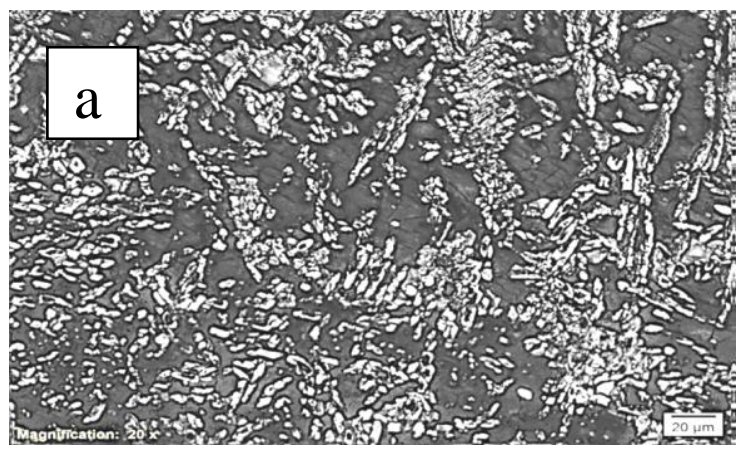

ER 2209-Weld metal

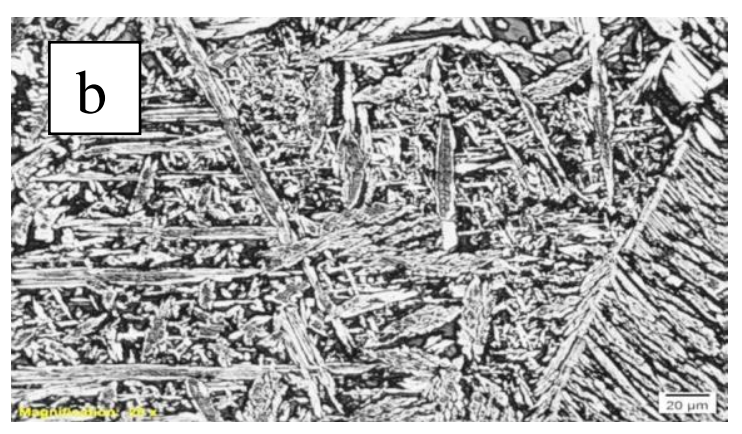

ER 2209- HAZ

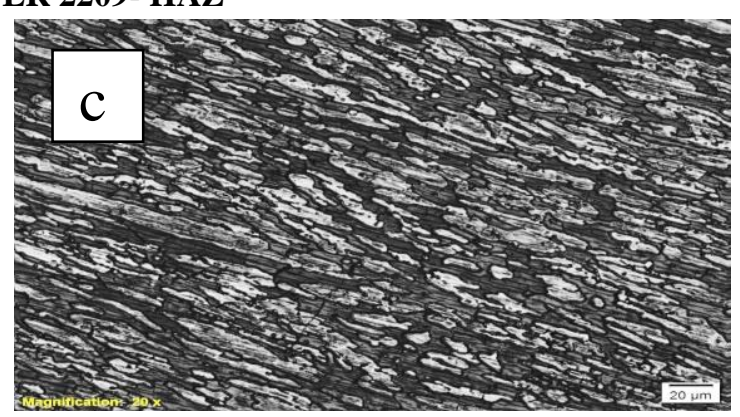

ER 312 - HAZ

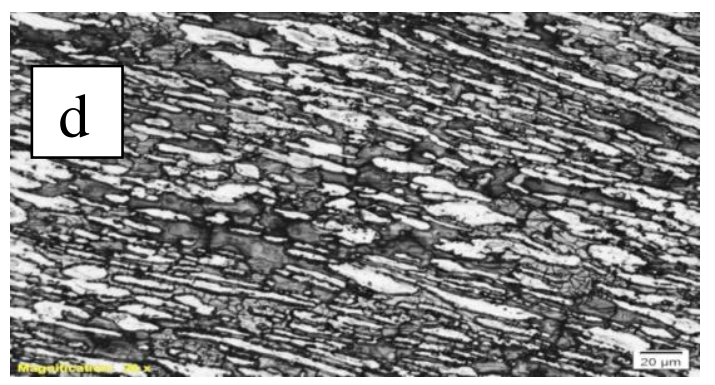

\section{D.s.s base metal}

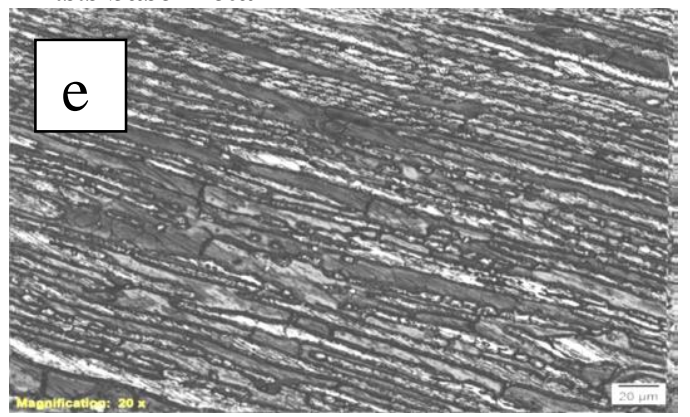

Fig 4: The microstructure of weld metals: (a) specimen ER 312 - Weld metal; (b) specimen ER 2209 - Weld metal; (c) specimen ER 2209- HAZ; (d) specimen ER 312 - HAZ ; (e) D. s. s base metal.

\subsection{Tensile test}

Specimen ER 312 had higher tensile strength and yield strength than specimen ER 2209 as shown in Figure 5(860, 720vs. 745,565 MPa). Besides, the mentioned ferrite values had a significant influence on the mechanical properties. The lowest amount of ferrite shows that Specimen ER 2209 is the weakest behavior during tensile tests.

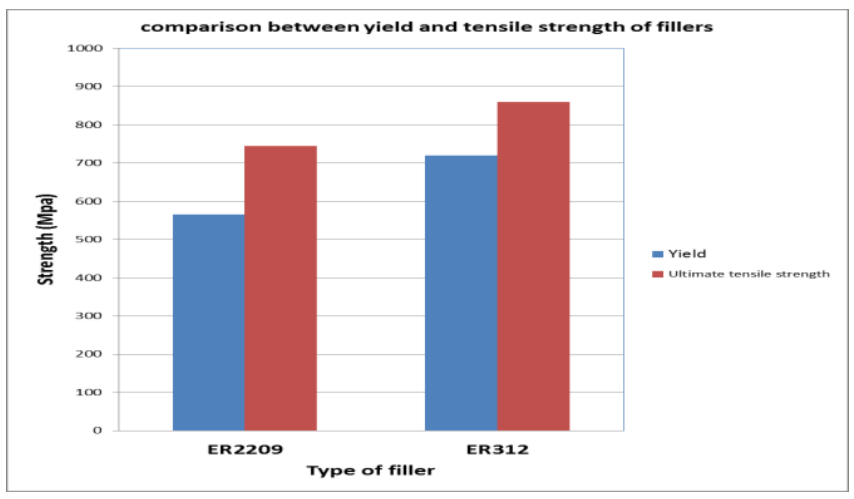

Fig 5: comparison between; yield and tensile strength of fillers 
Impact test results for HAZs and weld metals using different filler metals are given in Fig. 6. Specimen welded using ER 312 filler metal revealed that the austenite matrix absorbed the higher impact energy at $-20{ }^{\circ} \mathrm{C}(126 \mathrm{~J})$ than Specimen welded using ER2209 filler wire with a mixed ferritic and austenitic microstructure (51 J). Surprisingly, HAZ for Specimen ER2209 had the higher absorbed impact energy (167J) than the Specimen ER 312 (116J).

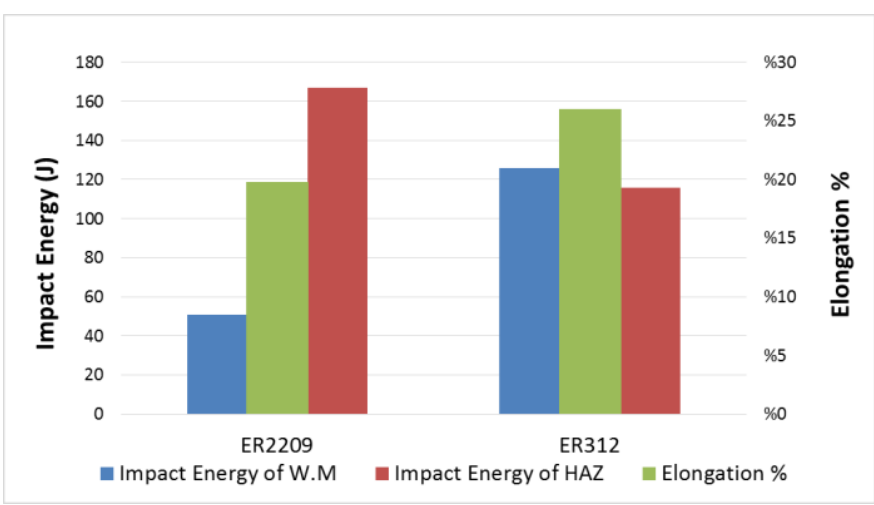

Fig 6: comparison between elongation and impact energy

$$
4 \text { CONCLUSION }
$$

Duplex stainless steel was welded using the GTAW process with two different fillers. After studying the microstructure and mechanical properties of the weld, the following conclusions were drawn:

1- The hardness of weld ER 2209 was higher than the hardness of ER 312 weld and then decreased from cap pass to root and vice versa. The ferrite content for the ER 312 was higher for the weld metal and HAZ than for the ER2209.

3- The secondary austenite, grain boundary austenite, and an amount of widmanstatten austenite were found in the microstructure of ER 2209 welds. In specimen ER 312 , the ferrite phase was the most prominent microstructural characteristic.

4- The maximum impact energy for W.M is obtained from the specimen welded with ER312, by raising the ferrite number; the absorbed energies of the impact test were reduced for ER 312, whereas the highest impact energy for HAZ is obtained from the specimen welded with ER2209. In specimens welded using ER2209, the lowest impact energy for W.M is determined.
5- Increased ferrite percent enhanced tensile strength values; specimen ER 312 had stronger tensile and yield strength than specimen ER 2209.

\section{ACKNOWLEDGMENT}

I would like to thank Eng. Sameh Helal ESAB Egypt Company for supplying the required fillers. And great thanks to Petrojet Company (Quality Assurance Department; Eng. Ahmed Abd El Aziz and Eng. Ayman Nadeem) for conducting the welding process and performing the radiographic tests on all welds.

\section{REFERENCES}

[1] S. Lamb, "CASTI handbook of stainless steels and nickel alloys. 2," 2002.

[2] P. UDARNE and I. D. NERJAVNEGA, "Impact-toughness investigations of duplex stainless steels," materials and technology, vol. 49, no. 4, pp. 481-486, 2015.

[3] I. Jirga, I. Stojanović i B. Ljubenkov, "EXPERIMENTAL RESEARCH OF THE DUPLEX STAINLESS STEEL WELDS IN SHIPBUILDING", Brodogradnja, vol.65, no. 2, pp. 73-85, 2014.

[4] Pilhagen, H. Sieurin, and R. Sandström, "Fracture toughness of a welded super duplex stainless steel," Materials Science \& Engineering, vol. 606, pp. 40-45, 2014.

[5] V. A. Hosseini, M. A. V. Bermejo, J. Gårdstam, K. Hurtig, and L. Karlsson, "Influence of multiple thermal cycles on microstructure of heat-affected zone in TIG-welded super duplex stainless steel," Welding in the World, vol. 60, no. 2, pp. 233-245, 2016.

[6] Ramkumar KD, Mishra D, Thiruvengatam G, Sudharsan SP, Mohan TH, Saxena V, Pandey R, Arivazhagan N " Investigations on the microstructure and mechanical properties of multi-pass PCGTA welding of super-duplex stainless steel". pp. 38, 2015.

[7] D. H. Kang and H. W. Lee, "Effect of different chromium additions on the microstructure and mechanical properties of multipass weld joint of duplex stainless steel," Metallurgical and Materials Transactions A, vol. 43, no. 12, pp. 4678-4687, 2012.

[8] V. Muthupandi, P. B. Srinivasan, V. Shankar, S. Seshadri, and S. Sundaresan, "Effect of nickel and nitrogen addition on the microstructure and mechanical properties of power beam processed duplex stainless steel (UNS 31803) weld metals," Materials Letters, vol. 59, no. 18 , pp. 2305-2309, 2005.

[9] J. Pilhagen and R. Sandström, "Influence of nickel on the toughness of lean duplex stainless steel welds," Materials Science and Engineering: A, vol. 602, pp. 49-57, 2014.

[10] V. Muthupandi, P. B. Srinivasan, S. Seshadri, and S. Sundaresan, "Effect of weld metal chemistry and heat input on the structure and properties of duplex stainless steel welds," Materials Science and Engineering: A, vol. 358, no. 1-2, pp. 9-16, 2003.

[11] Funderburk, R.S., "Key concepts in welding Engineering A look, at heat input", Welding Innovation, Vol 16, pp.1-4, 1999.

[12] ASM handbook, Metallography and Microstructures, Vol.9,9 edition , ASM international, materials park ,OH, 2004.

[13] ASTM standard E23, " standard test methods for notched bar impact testing of metallic materials " West Conshohocken, PA, USA, 2002.

[14] ASTM standard E8M, "standard test methods for tension testing of metallic materials" West Conshohocken, PA, USA, 1998. 